Lepr Rev (2000) 71, 206-211

\title{
Leprosy elimination at sub-national level
}

\author{
REINALDO E. GIL SUAREZ \& CLOVIS LOMBARDI* \\ Short-Term Consultant, Leprosy, PAHO/WHO, Brazil \\ *Leprosy Regional Adviser, PAHO/WHO, Brazil
}

Accepted for publication 24 February 2000

\begin{abstract}
Summary New strategies for the countries that have already achieved the elimination goal, which includes the great majority of the endemic countries, are needed. There is current concern in these countries about the reduction in the political-technical commitment when the goal is achieved and the possibility of the re-emergence of the disease. A review of the literature on the leprosy postelimination strategy is done. The proposal to estimate the true prevalence using hidden prevalence based on late diagnosis of the new cases is made. Suggestions are explored for strategies of the work after elimination at national level is attained such as the stratification at the first sub-national level, using estimated true prevalence. It is considered necessary to define strategies for the post-elimination phase with the aim of continuing to the long-term objective of the interruption of transmission and the consequent leprosy eradication.
\end{abstract}

\section{Introduction}

Significant advances have been achieved by the great majority of the leprosy endemic countries towards the objective of leprosy elimination as a public health problem (prevalence rate less than 1 per 10,000 inhabitants) at national level. The countries now need to establish new strategies for the time when they have achieved this objective.

Near the end of $1997,{ }^{1}$ about half (35) of the countries with more than 100 registered cases have achieved a prevalence rate of less than 1 per 10,000 inhabitants at the national level. In another 17 countries $(24.6 \%)$ the prevalence rate was less than 2 per 10,000 inhabitants and can be expected to attain the goal of elimination in the near future.

The elimination at national level can be considered as the intermediate objective that played an important role in producing a radical change in the work of leprosy control in almost all endemic countries. The political commitment of the governments and funding by governments and by the NGOs (non-governmental organizations) increased. However, this should not be considered the final objective of the work in leprosy. On the other hand, international experience shows that when disease control targets are reached, there is a tendency for activities to decrease. Complacency in considering that the problem has been solved can lead to its return as a re-emergent disease. ${ }^{2-5}$

Correspondence to: R. E. Gil Suarez, STC-Projeto Lepra, OPAS-OMS, Setor de Embaixadas Norte Lote 19, 70800-400 Brasilia-DF, Brasil (e-mail: suarezrg@opas.org.br) 
This situation has been analysed on many occasions, as in the Hanoi Declaration of $1994,{ }^{6}$ recommending the preparation of the post-elimination phase. Smith ${ }^{7}$ emphasizes that leprosy will continue being a problem after the year 2000, and the need for planning the requirements of the next phase. Khalafalla ${ }^{8}$ emphasizes the necessity of a strategy by WHO and other relevant agencies to face the problems that will appear after the year 2000, while Lechat ${ }^{9}$ indicates that the final objective of leprosy control is the interruption of the transmission. A recent article published by TDR News ${ }^{10}$ illustrates how '... the success of the elimination strategy leads to thinking, in some areas of the world, that the disease is eradicated'.

At the national technical meeting on the post-elimination stage ${ }^{11}$ held in 1993 in Cuba, a country close to achieving elimination, the main actions were established to start programming the activities in this stage. Among the proposals were the following recommendations:

1. To define a 3-year transition step to validate the elimination.

2. To estimate the hidden prevalence on the basis of the proportion of new cases detected late.

3. To prepare a new stratification based on the estimated prevalence.

4. To establish priorities at provincial, municipality, health areas and family doctor sector levels.

At the PAHO-WHO Conference on Leprosy Elimination of the Americas, $1996,{ }^{12}$ the representatives of some countries expressed their concern for the fact that leprosy as a priority had reduced considerably when elimination was achieved, without establishing a strategy for the next stage.

At the Second WHO International Conference on leprosy elimination, held in India, ${ }^{13}$ it was established that '...the countries which had achieved the goal of elimination at national level, should focus their attention on the objective of attaining elimination at sub-national level as well as maintaining adequate training and rehabilitation activities. This is important to guarantee that the services are able to assure the continuity in the detection and treatment of new cases, and respond to the medical and social necessities of the individuals affected by the disease. The efforts to assure the elimination of leprosy as a public health problem will establish the basis for leprosy eradication in the future'.

Another aspect that has been emphasized in the literature is the possibility of the existence of a hidden prevalence, ${ }^{14-16}$ related to the disease characteristics and the existence of operational problems in the performance of actions in many countries of the world. ${ }^{16-24}$ According to WHO data ${ }^{25}$ for the year 1997, the hidden prevalence in the world was estimated to be more than 250,000 cases spread in all regions of the world and in the majority of the endemic countries. WHO has proposed to support in the implementation of LEC (Leprosy Elimination Campaign) projects ${ }^{15}$ with the objective to identify and begin the treatment with MDT (Multi-Drug Therapy) for the hidden patients.

The aim of elimination as a public health problem is based on the known prevalence or registered prevalence, ${ }^{14}$ taking into consideration that it is difficult to know the true prevalence. Despite the efforts made, it is possible that many countries that have achieved elimination have an unknown prevalence. In the post-elimination phase, it is important to consider this situation and try to estimate the true prevalence, thus it is necessary to have methods to estimate this hidden prevalence. ${ }^{16,19,23,26-28}$

It is important to analyse possible strategies for the post-elimination phase, and to develop practical methods of estimating true prevalence using the estimate of the hidden prevalence. 
This paper represents a proposal to address this situation by means of elimination at the sub-national level, including methods to approach estimations of leprosy true prevalence through the estimated hidden prevalence.

\section{Estimating real prevalence of leprosy}

\section{RATIONALE}

It is accepted that the great majority of leprosy patients when diagnosed early do not show evidence of disabilities. $7,16,19,20,24,29-32$ The percentage of the cases diagnosed with a grade of disability (including grade 1) can be considered to be a late diagnosis. It is assumed in this proposal that the percentage of new leprosy cases with some disability, among the ones who were evaluated to measure disabilities, can represent an indicator of patients who have not been detected, when applied to the total of new cases detected in the same year.

Assuming an average incubation period of the disease, the sum of the previous 5 years to the year in which we want is used to estimate the hidden prevalence.

It should be taken into account that early diagnosis will be influenced by operational factors (programmes with low performance do not manage to detect cases in the early stages). Therefore with this indicator, the operational component of the problem will be evaluated. Late diagnosis will favour the maintenance of infection sources in the community.

In short, it has been considered that the extent of the leprosy hidden prevalence will be influenced by epidemiological and operational elements, and both of them can be assessed using the percentage of new cases detected with a grade of disability.

\section{METHODOLOGY}

The estimated rate of the true prevalence of leprosy is obtained by adding the known or registered prevalence, and the estimated hidden prevalence.

\section{Estimated real prevalence $=$ Registered prevalence + Hidden prevalence}

To estimate the hidden prevalence, we apply the percentage of new patients with any disability (among the ones who were evaluated), to the total of new patients detected. This requires a high proportion of new cases to be accurately assessed. This procedure is used from the previous 5 years to the year we want to estimate. Table 1 summarizes the proposal for collating the necessary information.

When there are interventions to detect the hidden prevalence based on the proposed

Table 1. Chart used to provide estimate of hidden prevalence of leprosy

\begin{tabular}{llllll} 
Indicator/year & $19-$ & 19 & $19-$ & $19-\quad 19-\quad$ Total \\
\hline
\end{tabular}
a) New cases
b) Evaluated
c) Disabled G, 1,2
d) Percentage of disabled (c/b)\%
e) Estimate of non-detected cases $(d \times a) / 100$ 
estimation, the evaluation would be related to the number of new cases detected, which should be the same as the sum of estimated hidden prevalence and the usual number of cases detected in the studied area.

\section{Proposal for different strategies at sub-national level}

When elimination at national level in a country is achieved, it is necessary to define the possible action scenarios at the first sub-national level (states, provinces, departments), based on the estimation of the true leprosy prevalence. Possible scenarios are that leprosy has not been eliminated, leprosy has been eliminated using MDT, and leprosy was not a problem.

A general strategy should be based on: a) the decentralization of leprosy component actions to the health units at the municipalities (districts); b) the health authorities of the municipality (district) assume responsibility for the management and co-ordination of the actions; and c) the work is done in an integrated way in basic health actions. In large municipalities (districts), defined by geographical area and population size and having many health units, it will also be possible to arrange an internal stratification, giving priority to leprosy actions. For the stratification in this municipality (district) category, it will also be necessary to take into account the possibility of having different health nets (subordinated to the municipality, to other government level, philanthropic or private), in which the patients can be managed or exclusively in one of the nets.

SCENARIO 1: LEPROSY HAS NOT BEEN ELIMINATED.

Implementation and/or strengthening of the Plans of Elimination at the first sub-national level. Health personnel capacity building, strengthening of programme management, and education of the population are still the main actions, with targets of early detection of patients and treatment with MDT/WHO to achieve the cure, to prevent disabilities and to interrupt transmission.

The special interventions such as the WHO projects LEC (Leprosy Elimination Campaign) and SAPEL (Special Action Programme for the Elimination of Leprosy), are still valid based on the existing criteria.

SCENARIO 2: LEPROSY HAS BEEN ELIMINATED BY MDT

Redefinition of the targets

Establishing as a new target a rate of leprosy prevalence less than 1 per 100,000 inhabitants.

\section{Analysis of the transmission trends}

Based on new case detection trends, the proportion of multibacillary leprosy and the age average in a period of not less than 10 years, it is possible to make an analysis that allows an estimate of leprosy transmission.

To make this analysis valid, there should be a correlation between the trends and the three indicators, in that when transmission is decreasing, a) a reduction in case detection; b) an increase of the proportion of $\mathrm{MB}$ forms, and c) an increase of the age average is 
observed. Where this correlation does not exist, it can be considered that the reduction in detection is likely to be a product of operational factors.

\section{Implementation of a net of sentinel centres}

Selection of a group of health units spread across the territory can be made to act as leprosy sentinel centres doing negative notification, possibly considering the presence of skin insensitivity as a sentinel event, reporting the number of patients with this symptom resulting in negative leprosy diagnosis.

The capacity of personnel in these health units will be strengthened in suspecting and confirming of the diagnosis, classification of the disease, the administration of MDT, managing reactions and relapses, and the preventing of disabilities.

\section{MDT drug supply}

To guarantee MDT drugs supply in small quantities, according to the level of disease prevalence.

\section{Silent areas}

In areas where leprosy has been eliminated as a health problem and no new cases are notified, special interventions will be planned in order to confirm if there is interruption in the transmission or if because of operational reasons why cases are not being diagnosed.

\section{SCENARIO 3: LEPROSY WAS NOT A PROBLEM BEFORE MDT}

This refers to those areas where no new leprosy cases have been registered in the last 10 years, which can be considered as non-endemic, and in which no special activity is required except routine epidemiological vigilance.

\section{Comments}

It is necessary to define strategies to continue the work in leprosy when elimination has been achieved at national level. When this target is reached, a new phase begins with the objective to achieve elimination at the first sub-national level. The objective of achieving the support for the sustained leprosy activities by integration with primary health needs to be based on estimated true prevalence and the different scenarios. The design and implementation of an adequate epidemiological vigilance system of the cases, relapses/reactions and disabilities, needs to keep going until the target of interruption of transmission is achieved.

\section{References}

1 WHO. Progress towards leprosy elimination. Wkly Epidemiol Rec, 1998; 73: 153-160.

2 Berkerman RL, Hughes JM. The conquest of infectious diseases: who are we kidding? Ann Int Med, 1993; 119: $426-428$. 
${ }^{3}$ Schwartz DA, Bryan RT, Hughes JM. Pathology and infections-Quo vadimus? Am J Pathol, 995; 142: 1525-1533.

${ }^{4}$ Morse SS. Factors in the emergence of infectious diseases. Emerg Infect Dis, 1995; 1: 15.

5 ILEP. Sostenimiento de las actividades de lepra. Pautas para responder al cambio. ILEP, London, 1997, p. 7.

6 WHO. Report of the International Conference on the Elimination of Leprosy. WHO, Hanoi, Vietnam, 1994 (WHO/CTDILEP/94.5).

7 Smith WCS. Optimism justified but realism indispensable. Round table. World Health Forum, 1996; 17: $122-126$.

${ }^{8}$ Khalafalla G. The optimism is perhaps justifiable. Round table. World Health Forum, 1996; 17: 131-132.

9 Lechat MF. The effort itself is already more than justified. Round table. World Health Forum, 1996; 17: $139-142$.

${ }^{10}$ WHO. Leprosy: from elimination to eradication? TDR News, 1996; 49: 3.

11 Ministerio de Salud Pública-Cuba. Informe de la Reunión Técnica sobre la etapa de post-eliminación de la lepra. Habana, 1993 (Mimeografiado).

12 OPS. Eliminación de la lepra de las Américas: situación actual y perspectivas. Informe de la Conferencia OPS/ OMS sobre la Eliminación de la Lepra de las Américas. Brasilia, 1996 (Mimeografiado).

13 WHO. Recommendations. Report of the second Conference on Elimination of Leprosy. WHO, New Delhi, India, 1997 (WHO/LEP/97.1).

14 Smith WCS. We need to know what is happening to the incidence of leprosy. Lepr Rev, 1997; 68: 195-200.

15 WHO. Guidelines for carrying out Leprosy Elimination Campaigns. WHO, Geneva, 1996 (LEC-10.01.96) (Mimeografiado).

16 OPS/OMS. Informe de la Reunión Técnica de Lepra sobre: 'La Eliminación de la Lepra como Problema de Salud Pública a nivel sub-nacional/post-eliminación de La lepra'. La Habana, Abril de 1998 (Mimeografiado).

17 OMS. Guía para la eliminación de la lepra como problema de salud pública. WHO, Geneva, 1997 (WHO/LEP/97.7).

18 Talhari S, Neves RG. Hanseníase. In: Lombardi C, Gil Suárez RE (eds) Epidemiologia da Hanseníase, 3rd edn. Gráfica Tropical, Manaus, 1997, pp. 128-136.

19 Lombardi C, Ferreira J, Motta CP, Oliveira MLW. Hanseníase, Epidemiologia e Controle. Imprensa Oficial do Estado, São Paulo (Brasil), 1990.

20 Hastings RC. Leprosy. In: Noordeen SK (ed.) The epidemiology of leprosy. Churchill Livingstone, London, 1985, pp. 15-30.

21 Gil Suárez R, Hernández O, De Rojas V. Programa de control de lepra para el médico de la familia. 2 ed. Ministerio de Salud Pública, Habana, 1994.

22 Gil Suárez R. Notas sobre Ia Epidemiología de la Lepra. OPS/OMS, Washington, (PNSP 89-42).

${ }^{23}$ WHO. Report of Second International Conference on the Elimination of Leprosy. WHO, Geneva, 1997 (WHOILEP/97.1).

${ }^{24}$ Noordeen SK. Eliminación de la lepra como problema de salud pública. Una perspectiva global. Informe de la Conferencia OPS/OMS sobre la Eliminación de la Lepra de las Américas. Brasilia, 1996 (Mimeografiado).

${ }^{25}$ WHO. Action programme for the elimination of leprosy. Status report, updated 1997. WHO, Geneva, 1997 (WHOILEP/97.4).

26 OMS. Comité de Expertos de la OMS en Lepra. Sexto Informe. OMS, Ginebra (Serie de Informes Técnicos 768, 1988).

27 WHO. Expert Committee on Leprosy. Seventh Report. WHO, Geneva, 1998 (Technical Report Series 874).

28 WHO. Guidelines for conducting a leprosy elimination programme review. WHO paper presented at the $1 \mathrm{st}$ International Conference on the Elimination of Leprosy, Hanoi, 1997.

29 Noordeen SK. Eliminating leprosy as a public health problem - is the optimism justified? World Health Forum, 1996; 17: 109-118.

30 Summers A. Leprosy for field staff. TALMILEP, London, 1993.

31 WHO. Global strategy for the elimination of the leprosy as a public health problem. WHO, Geneva, 1996 (WHOILEP/96.7).

32 OMS. Quimioterapia de la lepra. Informe de un Grupo de Estudio de la OMS. OMS, Ginebra, 1994 (Serie de Informes Técnicos 847).

33 WHO. Elimination of leprosy. Questions and answers. WHO, Geneva, 1996 (WHO/LEP/96.4). 